\title{
Deep crustal structure along the Niigata-Kobe Tectonic Zone, Japan: Its origin and segmentation
}

\author{
Junichi Nakajima and Akira Hasegawa \\ Research Center for Prediction of Earthquakes and Volcanic Eruptions, Graduate School of Science, Tohoku University, Sendai 980-8578, Japan
}

(Received October 12, 2006; Revised December 8, 2006; Accepted December 13, 2006; Online published March 21, 2007)

\begin{abstract}
A seismic tomography study has revealed a detailed three-dimensional seismic velocity structure along a highstrain-rate zone, the Niigata-Kobe Tectonic Zone (NKTZ), located in Japan. The results show that the depth extent of the low-velocity zone varies along the NKTZ. We divided the NKTZ into three regions on the basis of the velocity structure. A low-velocity anomaly observed in the lower crust beneath the southwestern part of the NKTZ is probably attributable to the fluids derived from the Philippine Sea slab, while a prominent low-velocity anomaly extending from the upper crust to the uppermost mantle in the volcanic region, the middle part of the NKTZ, may be caused by the existence of melts and a higher-temperature condition that results from magmatic activity. The northeastern part exhibits low-velocity anomalies in the upper crust and the uppermost mantle, which are probably due to the thick sediment and fluids related to the back-arc volcanism, respectively. The strength of the crust and uppermost mantle along the NKTZ may have been weakened by the concentration of the fluids, which in turn facilitates the large contraction there. The heterogeneous structures revealed in this study suggest that the origin of the high-strain-rate zone varies along the NKTZ.
\end{abstract}

Key words: Seismic tomography, low-velocity zone, Niigata-Kobe Tectonic Zone, deformation, fluids.

\section{Introduction}

The GEONET (GPS Earth Observation NETwork) operated by the Geographical Survey Institute of Japan has revealed that a zone of high strain rates, called the NiigataKobe Tectonic Zone (NKTZ), extends from Niigata to Kobe (Fig. 1) (Sagiya et al., 2000). This high-strain-rate zone, which is approximately $500 \mathrm{~km}$ long in the NE-SW direction and approximately $100 \mathrm{~km}$ wide, undergoes contraction in the WNW-ESE direction (approx. 107 year-1). The contraction rate is a few fold larger than that in the surrounding regions. The existence of such a zone has also been revealed in the analyses of triangulation data over the past 100 years (e.g. Hashimoto and Jackson, 1993).

The observed horizontal displacement rates in the NKTZ have been discussed in terms of an interplate deformation (e.g., Shimazaki and Zhao, 2000) and intraplate deformation (e.g., Iio et al., 2002; Yamasaki and Seno, 2005). Iio et al. $(2002,2004)$ proposed a model in which a weak zone with low viscosity exists in the lower crust. Using a threedimensional (3-D) viscoelastic finite element model, Hyodo and Hirahara (2003) showed that the high strain rates in the zone can be attributed to the $15-\mathrm{km}$-thick viscoelastic lower crust having almost the same viscosity as that of the upper mantle. In their model, the viscosity in the upper mantle was assumed to be uniform, and the overriding plate was loaded by interseismic locking and unlocking of the Pacific plate. Yamasaki and Seno (2005) evaluated the effects of viscosity heterogeneities in the lower crust and upper man-

Copy right(c) The Society of Geomagnetism and Earth, Planetary and Space Sciences (SGEPSS); The Seismological Society of Japan; The Volcanological Society of Japan; The Geodetic Society of Japan; The Japanese Society for Planetary Sciences; TERRAPUB tle on the surface deformation along the NKTZ, assuming that the high-strain-rates zone is produced by the subduction of the Philippine Sea plate. Their results show that a low viscosity of the upper mantle beneath and trenchward of the NKTZ accounts for the observed high strain rates, with implications for the importance of viscosity heterogeneities in the upper mantle.

We applied travel-time tomography to the high-quality travel-time data recorded at the nationwide seismograph network in Japan to reveal a detailed seismic velocity structure of the crust and uppermost mantle beneath the NKTZ, which is essential to develop better quantitative models for the zone. This study provides important insights into the factors controlling the strain accumulation process associated with the NKTZ.

\section{Data and Method}

A large number of high-quality $P$ - and $S$-wave arrival times generated from 4,413 earthquakes were used in the travel-time tomography (Fig. 2). We picked the arrival times for 3,220 earthquakes that occurred during the period from January 2001 to December 2005 and obtained 303,552 $P$ - and 201,114 $S$-wave arrival times. In addition, the arrival times picked by the Japan Meteorological Agency (JMA) (33,871 $P$ - and 15,942 $S$-wave arrivals) were used for 1,193 earthquakes with a depth greater than $100 \mathrm{~km}$ that occurred between October 1997 and December 2000. The latter data set offers a better ray coverage for the deeper part of the study region. A total number of 796 seismograph stations were used in this study (Fig. 2). All of the stations are equipped with three-component, shortperiod seismometers. The data reading accuracy is $0.05-0.1$ 


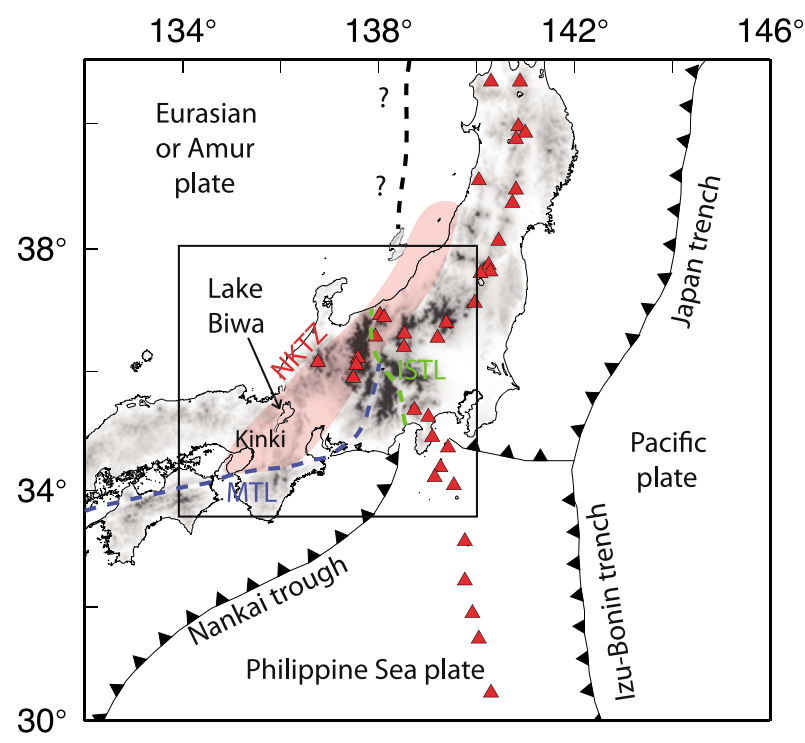

Fig. 1. Tectonic setting around the Japanese Islands. The Niigata-Kobe Tectonic Zone (NKTZ) is denoted by a pink belt. The rectangle indicates the study area. The red triangles represent active volcanoes. The Itoigawa-Shizuoka Tectonic Line (ISTL) and the Median Tectonic Line (MTL) are shown by green and blue broken curves, respectively.

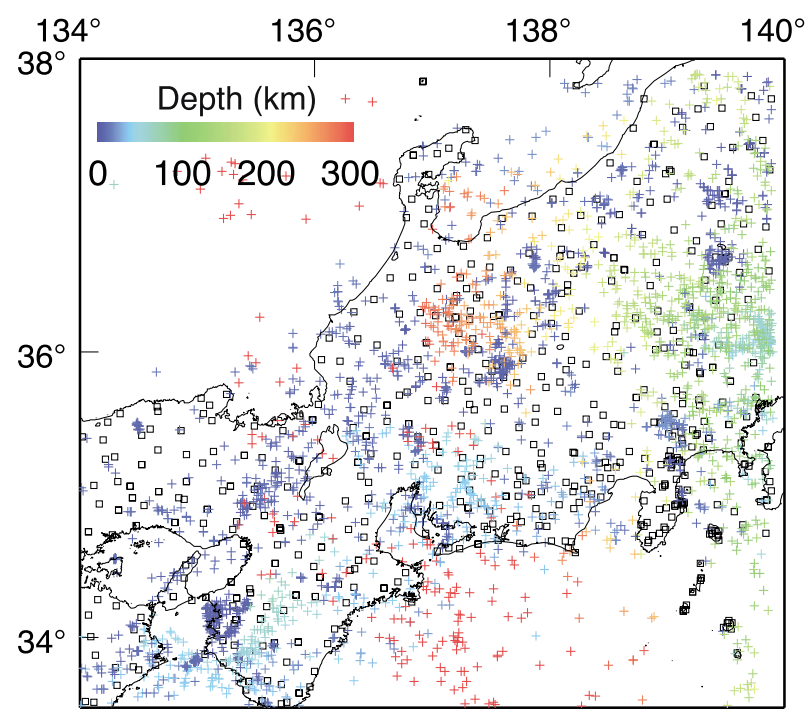

Fig. 2. Distribution of hypocenters (crosses) and seismograph stations (open squares) used in this study. The depth of the earthquakes is represented by the color scale.

s and $0.1-0.2 \mathrm{~s}$ for the $P$ - and $S$-wave arrivals, respectively.

In this study, we used the 3-D tomography method of Zhao et al. (1992a) to determine 3-D $P$ - and $S$-wave velocity structures. In the inversion, crustal discontinuities (Zhao et al., 1992b) and the upper boundary of the Pacific slab (Nakajima and Hasegawa, 2006) were taken into account. The velocity structure used in the JMA routine work (Ueno et al., 2002) was adopted as an initial $P$-wave velocity model. An initial $S$-wave velocity model was calculated by assuming a constant $V p / V s$ value of 1.73 . We set horizontal grid nodes in the model space with an interval of 0.2 ; vertical grid nodes were set with intervals of 5-15 km in a depth range of $0-40 \mathrm{~km}, 20 \mathrm{~km}$ in a depth range of 40-120 $\mathrm{km}$, and $30-50 \mathrm{~km}$ at greater depths. The final results were
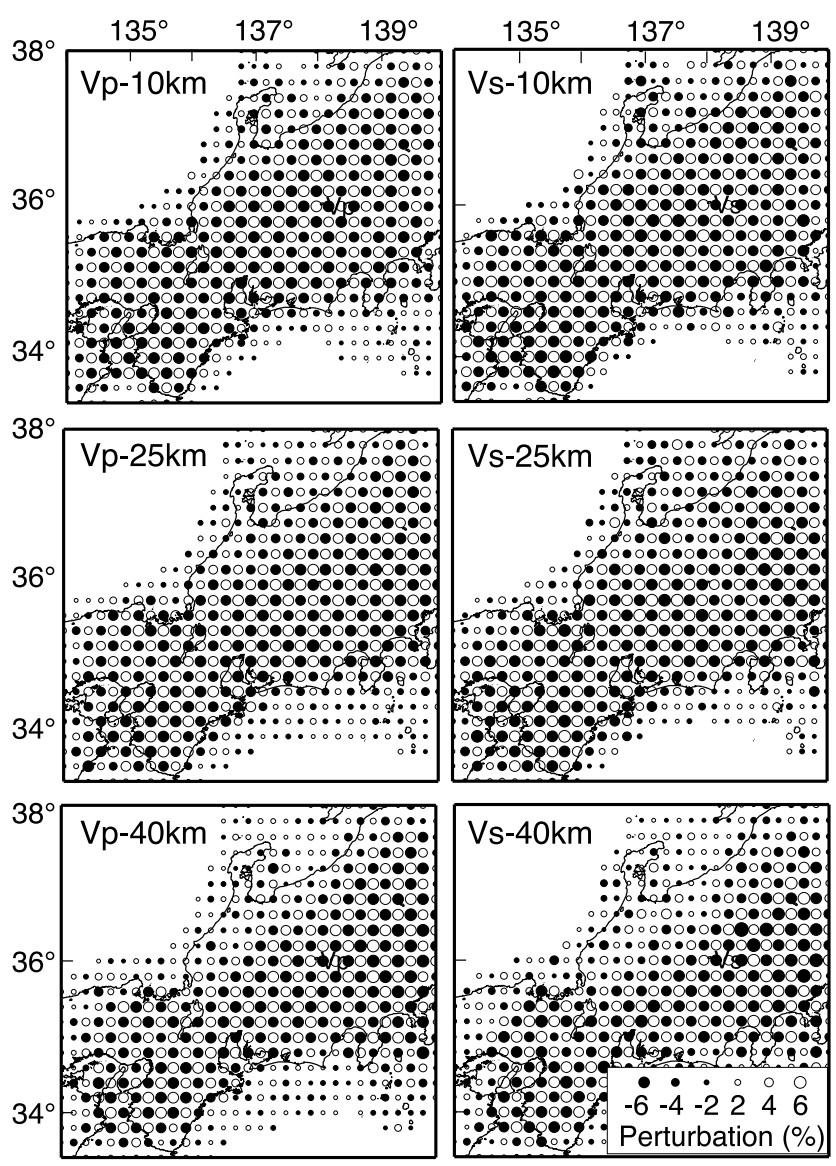

Fig. 3. Results of the checkerboard resolution tests of $P$ - and $S$-waves at depths of 10,25 , and $40 \mathrm{~km}$. The solid and open circles denote low and high velocities, respectively.

obtained after four iterations. The root mean square of the arrival-time residuals for the initial model $-0.32 \mathrm{~s}$ for $P$ waves and $0.58 \mathrm{~s}$ for $S$-waves-were reduced to $0.23 \mathrm{~s}$ and $0.41 \mathrm{~s}$, respectively, upon optimization.

\section{Results and Resolution Tests}

We conducted checkerboard resolution tests (CRTs) to ascertain the adequacy of the ray coverage and reliability of the obtained images. We assigned positive and negative velocity perturbations of $6 \%$ to alternate grid nodes and calculated travel times for this model to generate synthetic data. Random noises corresponding to the phase-picking errors (a standard deviation of $0.1 \mathrm{~s}$ for the $P$-wave and 0.15 $\mathrm{s}$ for the $S$-wave) were added to the synthetic data. Figure 3 shows the results of CRTs at depths of 10, 25, and 40 $\mathrm{km}$, respectively. The checkerboard patterns are well recovered at all depths, suggesting the reliability of the obtained velocity structure. We also conducted restoring resolution tests (RRTs) (Zhao et al., 1992a) on the obtained structure. The results of the RRTs demonstrate the reliability of the obtained images of the region beneath the land area.

The obtained seismic velocity structures show the existence of a highly heterogeneous structure along the NKTZ. Figure 4 depicts a map showing the $P$ - and $S$-wave velocity perturbations at depths of 10,25 , and $40 \mathrm{~km}$, which correspond to the upper crust, lower crust, and uppermost mantle, respectively. The velocity perturbations indicate 


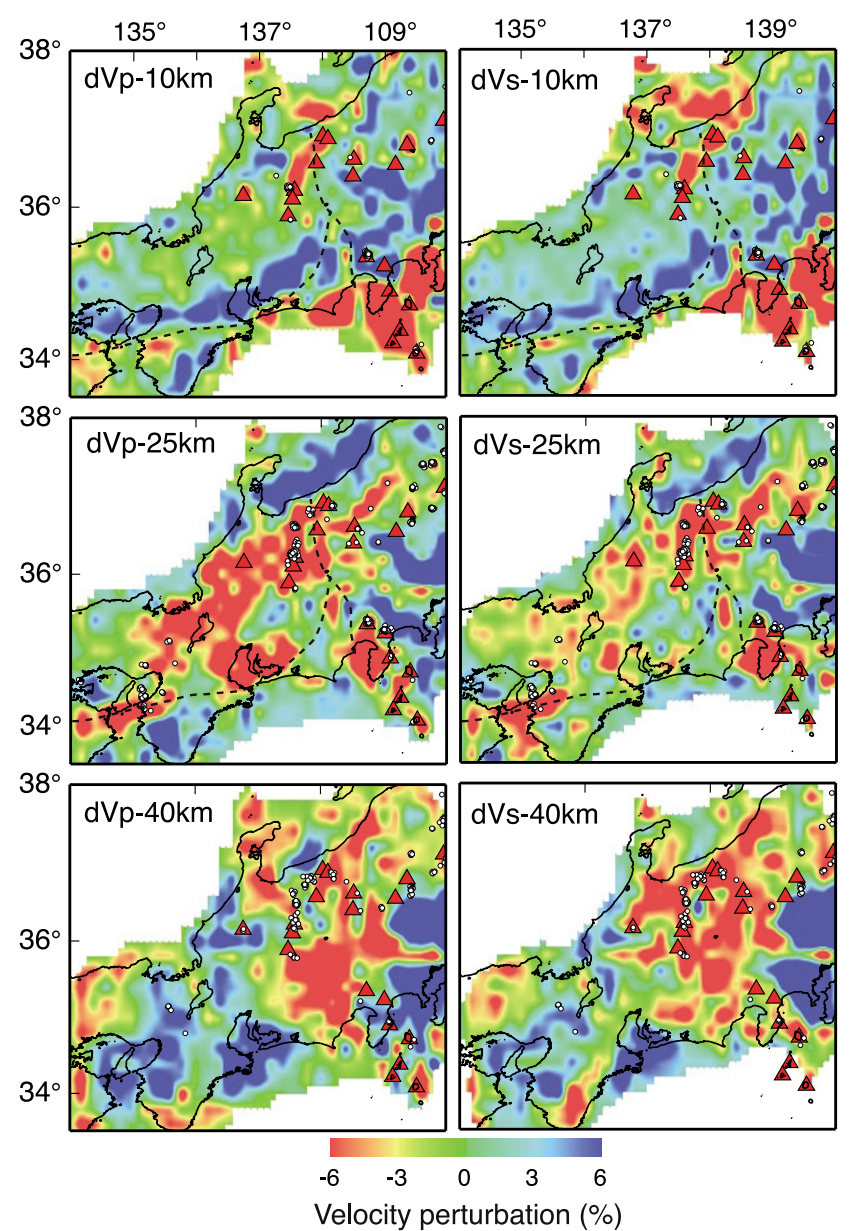

Fig. 4. $\quad P$ - and $S$-wave velocity perturbations at depths of 10,25 , and $40 \mathrm{~km}$. The red and blue colors denote low and high velocities, respectively. Low-frequency earthquakes determined by the JMA are shown by white circles. Note that low-frequency earthquakes associated with the subducted Philippine Sea slab are excluded. The broken black curves at depths of 10 and $25 \mathrm{~km}$ represent the ISTL and MTL.

a deviation from the average velocity at each depth. At a depth of $10 \mathrm{~km}$, prominent low-velocity zones are observed beneath the NKTZ around the Itoigawa-Shizuoka Tectonic Zone (ISTL). A high-velocity anomaly appears to be distributed along the north of the Median Tectonic Line (MTL), which is the longest fault in Japan, dividing southwest Japan into Inner and Outer Zones. A distinct low-velocity zone exists in the lower crust along the NKTZ, mainly at the southwest of the ISTL and particularly for the $P$-wave. The width of the zone is approximately 100 $\mathrm{km}$, which is comparable to the width of the NKTZ. The Philippine Sea slab subducted sub-horizontally to depths of 35-40 km around Biwa Lake (e.g., Miyoshi and Ishibashi, 2004) can be imaged as a high-velocity anomaly at a depth of $40 \mathrm{~km}$. The volcanic area in Central Japan exhibits a distinct low-velocity anomaly. Low-frequency earthquakes that occurred in the non-volcanic regions of the Kinki district as well as those occurring in the nearby volcanoes are distributed in and around the low-velocity anomalies.

\section{Discussion and Conclusions}

Figure 5 shows the vertical-cross sections of the $P$ - and $S$-wave velocity perturbations as well as the $V p / V s$ ratio
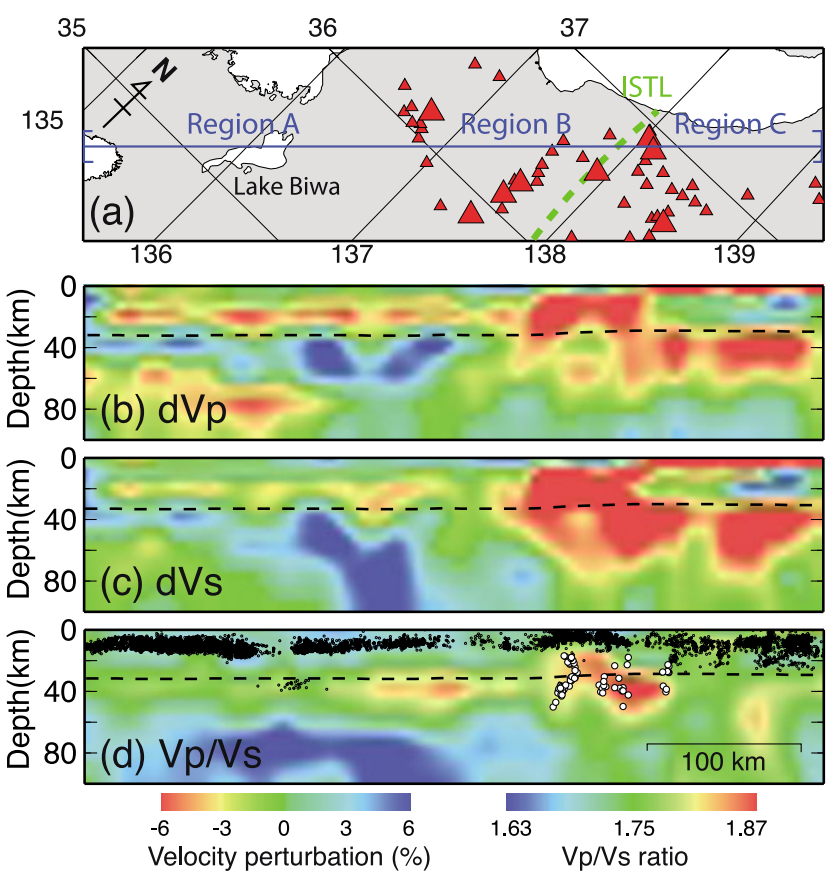

Fig. 5. (a) Location of the profile along the NKTZ for which the vertical cross sections of velocity structure are shown. Vertical cross sections of (b) $P$ - and (c) $S$-wave velocity perturbations, and (d) $V p / V s$ ratio along the profile in (a). The large and small red triangles in (a) denote the active and Quaternary volcanoes, respectively. Microearthquakes (dots) and low-frequency earthquakes (white circles) that occurred within a 10-km-wide zone along the profile are shown in (d). The broken line in each figure denotes the depth of the Moho adopted in the inversion (Zhao et al., 1992b).

together with seismicity along the NKTZ. It is evident that the velocity structures vary considerably along the NKTZ. Note that we carried out the inversion without crustal discontinuities in order to assess the effect of fixed crustal discontinuities on velocity structures and obtained results that show almost the same features, indicative of the robustness of the obtained velocity structures. The NKTZ is divided into three regions on the basis of the velocity structures: the southwestern part (region A), the middle part where volcanoes are concentrated (region B), and the northeastern part (region $\mathrm{C}$ ). The boundary between regions $\mathrm{B}$ and $\mathrm{C}$ roughly corresponds to the ISTL.

Miyoshi and Ishibashi (2004) argued that the Philippine Sea slab is subducted toward the northwest at a low-dip angle around Biwa Lake and that isolated earthquakes around Lake Biwa at a depth of approximately $40 \mathrm{~km}$ (Fig. 5(d)) occur within the subducted Philippine Sea slab. A highvelocity anomaly observed below the Moho in the northeastern half of region A probably reflects this subducted Philippine Sea slab. If intraslab earthquakes would occur as a result of dehydration embrittlement, aqueous fluids could be released from the slab to the overriding plate. A lowvelocity anomaly with a $V p / V s$ value of approximately 1.7 in the lower crust is explained by the existence of aqueous fluids there (Nakajima et al., 2001). We thus infer that the low-velocity zone in the lower crust is attributable to aqueous fluids released from the Philippine Sea slab.

The low-velocity zone extending from the upper mantle to the upper crust beneath region $\mathrm{B}$ is probably associated 
with the magmatic activity in this region. The fluids derived from the Pacific and the Philippine Sea slabs induce partial melting in the mantle wedge (Iwamori, 2000). The generated melts are transported through the mantle return flow to the uppermost mantle and partly intrude the crust, which reduces the seismic velocity and causes volcanic activity at the surface. A high- $V p / V s$ value of approximately 1.85 in the lower crust is similar to that observed in the volcanic region of northeastern Japan (Nakajima et al., 2001). Ogawa and Honkura (2004) detected a deep crustal conductor beneath the volcanic region at the west of the ISTL. These observations may suggest the existence of the magmatic fluids in the lower crust and uppermost mantle under a possible high temperature condition.

It is inferred that the low-velocity anomaly observed in the uppermost mantle in region $\mathrm{C}$ is caused by the existence of fluids derived from the Pacific slab, which is related to the volcanism in the back-arc side (Hasegawa and Nakajima, 2004). The low-velocity zone in the upper crust appears to reflect the Niigata sedimentary basin, which was formed as a back-arc rift basin associated with the opening of the Sea of Japan and now contains more than $6 \mathrm{~km}$ of accumulated basin fill (e.g., Sato, 1994). A prominent lowvelocity anomaly is absent in the lower crust, which is in contrast with regions $\mathrm{A}$ and $\mathrm{B}$.

The existence of aqueous fluids or melts in the crust and uppermost mantle along the NKTZ may have reduced the strength of both the crust and uppermost mantle, which in turn may have promoted an anelastic deformation, even in the upper crust (Hasegawa et al., 2005), and contributed to the large contraction along the NKTZ. The results obtained in this study suggest that the model with a weak zone in the lower crust (Iio et al., 2002, 2004) could be applicable to regions $\mathrm{A}$ and $\mathrm{B}$ but that the heterogeneity in the uppermost mantle (Yamasaki and Seno, 2005) should be additionally included at least in region B. Although it is not evident how the thick sediment with a thickness of approximately $6 \mathrm{~km}$ affects the surface deformation in region $\mathrm{C}$, it would contribute to the surface deformation along the NKTZ. These spatial variations of heterogeneous structure along the NKTZ would enable us to develop better models for this high-strain-rate zone.

Acknowledgments. We would like to thank D. Zhao for providing us with the tomography codes. This manuscript was significantly improved through constructive reviews by T. Seno and M. Reyners. We used seismic data obtained from the National Research Institute for Earth Science and Disaster Prevention, Hokkaido University, Hirosaki University, Tohoku University, University of Tokyo, Nagoya University, Kyoto University, Kochi University, Kyushu University, Kagoshima University, the National Institute of Advanced Industrial Science and Technology, Tokyo Metropolitan Government, Shizuoka prefectural government, Kanagawa prefectural government, the City of Yokohama, Japan Marine Science and Technology Center, and the Japan Me- teorological Agency. This work was partially supported by a grant from the Ministry of Education, Culture, Sports, Science and Technology, Japan, and by the 21st Century COE Program, Advanced Science and Technology Center for the Dynamic Earth, at Tohoku University.

\section{References}

Hasegawa, A. and J. Nakajima, Geophysical constraints on slab subduction and arc magmatism, in The State of the Planet: Frontiers and Challenges in Geophysics, Geophys. Monogr. Ser., vol. 150, pp. 81-94, AGU, Washington, D.C., 2004.

Hasegawa, A. and J. Nakajima, N. Umino, and S. Miura, Deep structure of the northeastern Japan arc and its implications for crustal deformation and shallow seismic activity, Tectonophysics, 403, 59-75, 2005.

Hashimoto, M. and D. D. Jackson, Plate tectonics and crustal deformation around the Japanese islands, J. Geophys. Res., 98, 16149-16166, 1993.

Hyodo, M. and K. Hirahara, A viscoelastic model of interseismic strain concentration in Niigata-Kobe Tectonic Zone of central Japan, Earth Planets Space, 55, 667-675, 2003.

Iio, Y., T. Sagiya, Y. Kobayashi, and I. Shiozaki, Water-weakened lower crust and its role in the concentrated deformation in the Japanese Islands, Earth Planet. Sci. Lett., 203, 245-253, 2002.

Iio, Y., S. Takeshi, and Y. Kobayashi, Origin of the concentrated deformation zone in the Japanese Islands and stress accumulation process of intraplate earthquakes, Earth Plants Space, 56, 831-842, 2004.

Iwamori, H., Deep subduction of $\mathrm{H}_{2} \mathrm{O}$ and deflection of volcanic chain towards backarc near triple junction due to lower temperature, Earth Planet. Sci. Lett., 181, 41-46, 2000.

Miyoshi, T. and K. Ishibashi, Geometry of the seismic Philippine Sea slab beneath the region from Ise bay to western Shikoku, southwest Japan, J. Seismol. Soc. Jpn., 57, 139-152, 2004 (in Japanese with English abstract).

Nakajima, J. and A. Hasegawa, Anomalous low-velocity zone and linear alignment of seismicity along it in the subducted Pacific slab beneath Kanto, Japan: Reactivation of subducted fracture zone?, Geophys. Res. Lett., 33, L16309, doi:10.1029/2006GL026773, 2006.

Nakajima, J., T., Matsuzawa, A. Hasegawa, D. Zhao, Three-dimensional structure of $\mathrm{Vp}, \mathrm{Vs}$ and $\mathrm{Vp} / \mathrm{Vs}$ beneath the northeastern Japan arc: Implications for arc magmatism and fluids, J. Geophys. Res., 106, 2184321857, 2001.

Ogawa, Y. and Y. Honkura, Mid-crustal electrical conductors and their correlations to seismicity and deformation at Itoigawa-Shizuoka Tectonic Line, Central Japan, Earth Plants Space, 56, 1285-1291, 2004.

Sagiya, T., S. Miyazaki, and T. Tada, Continuous GPS array and presentday crustal deformation of Japan, Pageoph, 157, 2303-2322, 2000.

Sato, H., The relationship between late Cenozoic tectonic events and stress field and basin development in northeast Japan, J. Geophys. Res., 99, 22261-22274, 1994.

Shimazaki, K. and Y. Zhao, Dislocation model for strain accumulation in a plate collision zone, Earth Planets Space, 52, 1091-1094, 2000.

Ueno, H., S. Hatakeyama, T Aketagawa, J. Funasaki, N. Hamada, Improvement of hypocenter determination procedures in the Japan Meteorological Agency, Quart. J. Seism., 65, 123-134, 2002 (in Japanese).

Yamasaki, T. and T. Seno, High strain zone in central Honshu resulting from the viscosity heterogeneities in the crust and mantle, Earth Planet. Sci. Lett., 232, 13-27, 2005.

Zhao, D., A. Hasegawa, and S. Horiuchi, Tomographic imaging of $\mathrm{P}$ and S wave velocity structure beneath northeastern Japan, J. Geophys. Res., 97, 19909-19928, 1992a.

Zhao, D., S. Horiuchi, and A. Hasegawa, Seismic velocity structure of the crust beneath the Japan islands, Tectonophysics, 212, 289-301, $1992 \mathrm{~b}$.

J. Nakajima (e-mail: nakajima@aob.geophys.tohoku.ac.jp) and A. Hasegawa 